ДИМИТРИЧЕВА Ольга Ивановна - кандидат философских наук, старший научный сотрудник международной междисциплинарной научной лаборатории технологий социально-гуманитарных исследований, доцент кафедры философии, социологии и теории социальной коммуникации Нижегородского государственного лингвистического университета им. Н.А. Добролюбова (603950, Россия, г. Нижний Новгород, ул. Минина, 31A; Dimitr-olga@yandex.ru)

САВЧЕНКО Ирина Александровна - доктор социологическихнаук, доцент; начальникмеждународной междисииллинарной научной лаборатории технологий социально-гуманитарных исследований, профессор кафедры философии, социологии и теории социальной коммуникации Нижегородского государственного лингвистического университета им. Н.А. Добролюбова (603950, Россия, г. Нижний Новгород, ул. Минина, 31А); профессор кафедры психологии и педагогики Нижегородской академии МВД РФ (603144, Россия, г. Нижний Новгород, Анкудиновское ш., 3; teosmaco@rambler.ru)

УСТИНКИН Сергей Васильевич - доктор исторических наук, профессор; директор Приволжского филиала ФНИСЦ РАН (603000, Россия, г. Нижний Новгород, Холодный пер., 4.); начальник международной междисциплинарной научно-исследовательской лаборатории изучения мировых и региональных социально-политических процессов Нижегородского государственного лингвистического университета им. Н.А. Добролюбова; научный руководитель Высшей школы международных отношений и мировой политики Нижегородского государственного лингвистического университета им. Н.А. Добролюбова (603950, Россия, г. Нижний Новгород, ул. Минина, 31A; sv.ustinkin@gmail.com) ПИКУНОВ Олег Игоревич - студент магистратуры Нижегородского государственного лингвистического университета им. Н.А. Добролюбова (603950, Россия, г. Нижний Новгород, ул. Минина, 31А; pikunovnglu@yandex.ru)

\title{
АКТУАЛЬНОСТЬ ИДЕЙ ЧИКАГСКОЙ ШКОЛЫ В ФОКУСЕ ПРОЦЕССОВ УРБАНИЗАЦИИ И РУРАЛИЗАЦИИ
}

\begin{abstract}
Аннотация. Актуальность идей чикагской социологической школы обьясняется фрагментарностью сравнительных социологических исследований города и села и многократно возрастает на фоне современных процессов урбанизации и рурализации. История социологии города начинается в XIX в., однако сегодня авторитетные центры по изучению городских и сельских сообществ, городской и сельской культуры активно не развиваются.

Авторы показывают, что современные параллельные, но разнонаправленные процессы урбанизации и рурализации повышают степень актуальности идей чикагской школы.
\end{abstract}

Ключевые слова: социология города, городской стиль жизни, сельский стиль жизни, городские переселенцы, иерархия ценностей, рурализация, урбанизация

И зучение города как социального и культурного объекта является сферой интересов социологов, начиная с XIX в. Накоплен огромный исследовательский материал, позволяющий оценить культурную специфику различных городов. Вместе с тем актуальная проблема города и городского стиля жизни заключается в недостаточном развитии в отечественной науке авторитетных центров изучения городских сообществ и городской культуры [Шабаев и др. 2018]. Кроме того, в современных отечественных учебниках по общей социологии городская социология не представлена как отдельное и самостоятельное научное направление.

Можно возразить, что в социологии и смежных науках проблема урбанизации исследуется достаточно широко, однако сегодня параллельно урбанизации протекает и обратный процесс - рурализация, который в социально-духовном плане выражаются в переносе городской специфики повседневной жизни в 
село. Отметим, что современные процессы урбанизации/рурализации имеют достаточно причудливую природу. На фоне общей тенденции к прогрессу и технологизации они имеют достаточно регрессивный характер [Савченко 2013].

Для понимания происходящих процессов обратимся к идеям представителей чикагской школы в социологии. Выявим основные положения и методы научного поиска, которые актуальны и в настоящее время; проследим элементы круга интересов представителей чикагской школы. Они, как мы считаем, будут полезными для современных социологов для выяснения специфики городского стиля жизни, который, что нужно иметь в виду, сегодня становится характерным не только для города, но и для села.

На основе метода опроса (устного и письменного) представители чикагской школы изучали различные социальные группы - их установки и аттитюды (ценностные ориентации). Наибольшие достижения социологов чикагской школы связаны с исследованием ряда социальных проблем, специфических для городского стиля жизни. Метод наблюдения за расширением границ города позволил Р.Э. Парку прийти к выводу, что развитие города - это не просто процесс увеличения численности жителей: изменяются сущностные, бытийные явления. Рост города связан со стремлением горожан найти свое место в социальной структуре города [Парк 2006]. Проблемы крупных городов исследовались на примере Чикаго. В основу исследований крупного города положена концепция города, включающая в себя такие явления, как социальная мобильность, социальное взаимодействие и социальное пространство в их взаимосвязи [Парк 2011].

Под руководством Э. Берджесса изучение крупного города проводилось на примере Чикаго на основе метода социального картографирования. Уникальность чикагской социологической школы заключается в процессе обучения студентов, который проходил в совместных полевых исследованиях. Помогая в изучении структуры города, студенты на практике получали опыт проведения социологических исследований. Широкое привлечение студентов позволило составить большое число социальных карт города. Изучались и проблемные зоны, такие как места активной подростковой преступности, разрабатывались карты мест отдыха: танцевальных площадок, театров, открытых кинотеатров и пр. Изучались особенности жизни диаспор (итальянской, немецкой, китайской) и этнорасовых групп (афроамериканцы, мулаты), создавались карты их расположения. Э. Берджесс обратил внимание на трансформации культурной идентичности, а также на особенности языкового поведения и лингвистической динамики в условиях большого города [Савченко 2010].

Социологи чикагской школы решали проблемы большого города. Для этого было необходимо на первом этапе представить городскую структуру в систематизированном виде. Поскольку США переживали в то время наплыв эмигрантов и необходимо было решать проблемы, связанные с большим числом людей разных национальностей, культур, вероисповеданий на одной территории, то была создана программа «Город как социальная лаборатория», которая получила хорошую финансовую поддержку из различных источников.

Социологи поделили город Чикаго на 75 районов, включающих около 3 тыс. чел.; эти описания используются и поныне.

Э. Берджесс опирался в своей классификации районов на данные переписей населения города в 1930 и 1934 гг. Исследователя интересовала не специфика жизни и культурные особенности общин.

Для понимания факторов, способствующих росту города, Э. Берджесс изучал формы социальной мобильности: индивидуальную, групповую (семейную 
и профессиональную) и специфику функционирования городской и районной (муниципальной) власти. Помимо этого, социолог анализировал девиантное поведение и его восприятие в урбанизированных условиях жизни.

У. Огборн с его концепцией культурного разрыва (культурного лага) стал, как мы знаем, одним из первых представителей технологического детерминизма в социологии города и в социальной науке в целом. Огборн показал, что прогресс в материальной сфере идет гораздо быстрее по сравнению с трансформациями духовной культуры. Таким образом, стремительное развитие технологий определяет все социальные изменения, вплоть до образа мыслей людей. Огборн подготовил социологическое восприятие города как средоточия материальной культуры, где нравственно-созерцательная сторона жизни находится в провале, в капсуле. Село - источник и символ культуры, олицетворяющий «господство земли и детство души», тогда как город, «каменный и окаменяющий», - символ и апогей цивилизации [Шпенглер 2009: 29].

Важнейшее, на наш взгляд, открытие, сделанное представителями чикагской социологической школы, - это концептуализация понятия «городской образ жизни». Термин был введен Л. Виртом [Вирт 2016]. Анонимность социальных взаимодействий, частота и кратковременность встреч между разными людьми, поверхностность контактов, снижение значимости семьи и брака, уменьшение уровня социальной сплоченности людей, деградация обычаев, традиций, социального контроля, высокая концентрация и большая численность населения, социальная неоднородность - все это сущностные черты городского стиля жизни, на которые и сейчас опираются социологи при изучении этого феномена. Ученый противопоставил «городской образ жизни» сельскому.

По мысли Л. Вирта, предполагается создание особого городского образа жизни, а этот образ жизни, в свою очередь, становится культурным образцом, который усваивают горожане и население, проживающее за чертой города [Вирт 2016]. Таким образом, уже социологи чикагской школы отмечают, что город - это не только увеличение численности населения, город подразумевает особый стиль жизни, который распространяется не только на городское население, но и на население, проживающее за пределами города.

Л. Вирт в этом вопросе является последователем немецкого социолога Г. Зиммеля. Георг Зиммель писал: «Город равен совокупности оказанного им за его ближайшими пределами влияния. Это только и есть его настоящий объем, в котором выражается его бытие» [Зиммель 2002: 31]. Кроме того, Л. Вирт развивает идеи Г. Зиммеля о свободе и одиночестве в условиях города. Луис Вирт полагал, что, с одной стороны, личность в городе достигает некоторой независимости от контроля со стороны малых групп, но, с другой стороны, человек остается без чувства участия, свойственного объединенным сообществам. Более того, специфика существования города состоит в прагматичном подходе к личности, которая рассматривается с точки зрения пользы, а межличностное общение носит практичный характер. Умножение числа профессий является институциональным закреплением идей прагматизма, свойственных сущности города [Вирт 2016: 96]. Наряду с уменьшением роли социальной солидарности, городскому стилю жизни свойственно снижение значимости традиционных ценностей семьи, родственных связей и исчезновение института соседства [Вирт 2016: 105].

Следствием этого является научный интерес к различным субкультурам, которые не только территориально находятся на пространстве города, но и принадлежат субкультурам различных учреждений, профессий, религиозных общин. Город был представлен как многообразие субкультур, или мозаика таких «миров». 
Рассмотрим более подробно понятие «стиль жизни». Стиль жизни - комбинация образцов поведения индивида или общности (регулярно воспроизводимые черты, свойства, манеры, привычки, привязанности, вкусы, склонности), ориентированные преимущественно на повседневную жизнь.

Урбанистическому стилю жизни миграционные процессы свойственны в большей степени, чем сельскому. Большая горизонтальная и вертикальная мобильность, большее число различных социальных групп и субкультур увеличивают возможности стать членом какой-либо общности, организации, концентрацию культурных ценностей и т.д.

Образ жизни включает в себя, с одной стороны, культуру потребления, которая специфична у разных народов и социальных групп. С другой стороны, содержанием концепта «образ жизни» являются процессы физического, интеллектуального, эстетического и т.П. саморазвития, самосовершенствования человека, общение, формирование и развитие мировосприятия, социальная обрядовая практика и т.д.

Выясним различия городского и сельского стилей жизни. Урбанистический стиль жизни привлекателен наличием большого числа социальных групп и возможностями для личности проявить себя в разнообразном качестве, удобствами искусственной среды обитания, большим количеством накопленной культурной информации и легкостью доступа к ней. Сельский стиль жизни основывается на органичных, естественных процессах, устойчивых, «проверенных временем» ценностях межличностного общения, уважении к труду.

Итак, наиболее важные отличия этих стилей заключаются в различной мотивации социальной активности, иерархии ценностей, уровне культурных запросов, понимании комфорта.

Создание нового жизненного пространства, искусственного городского мира порождает и ряд изменений в восприятии окружающего мира. Этот феномен интересовал не только социологов, но и философов. Так, размышляя над данной проблемой, Х. Ортега-и-Гассет характеризовал современные массы как избалованные чувством вседозволенности, воспринимающие все как должное, не задумывающиеся о реальных (экологических, например) источниках своего комфорта и благополучия. Это ощущение составляет внутренний, душевный склад индивида, подсказывая формулу жизни: «жить - это полагаться на себя: все практически дозволено, ничто не грозит расплатой, и вообще никто никому не обязан» [Ортега-и-Гассет 1997: 45].

Иллюстрацией иерархии ценностей городского стиля жизни может служить следующий факт. В России в малых городах, как и в деревнях, сохранился обычай здороваться со всеми людьми, которые встречаются на улице, даже если вы с ними лично не знакомы.

Сейчас деревни - в том виде, в каком они существовали на протяжении столетий, - исчезают безвозвратно. Они превращаются в дачные поселения, куда люди приезжают из города отдохнуть на выходные или в отпуск. Соответственно, эти люди привозят с собой городской стиль жизни, т.е. привычку здороваться только со знакомыми. Мимо незнакомых проходят молча. По манере поведения можно определить, местный это или приезжий человек.

Таким образом, городской образ жизни распространяется и на маленькие поселки, маленькие города и деревни. Люди - как атомы, они разобщены и не знают, кто живет с ними в одном подъезде в многоквартирном доме.

Распространению городского стиля жизни на вымирающие деревни и небольшие города способствует развитие технологий. Интернет позволяет работать и получать образование, покупать и продавать не только в городе, но и находясь в любом месте, где есть связь. 
Происходит миграция не только из села в город, но и из города в село. Речь идет о процессе, который принято называть рурализацией.

В 2015 г. был представлен результат социологического исследования российской обратной миграции из городов в сельскую местность [Звягинцев, Неуважаева 2015]. Авторов социологического исследования интересовала мотивация миграции, оценка условий и исследование последствий для села. Были выделены следующие категории переселенцев: пенсионеры, «программные переселенцы», «беглецы», искатели качественной жизни. Исследователи отмечают одну из особенностей, которая характеризует переселенцев: формирование сообщества нового типа (сельско-городского). Как правило, это отдельные личности, которые стремятся реформировать село и не собираются мириться с неудобствами сельской жизни. Они как лидеры мнений объединяют вокруг себя сельское сообщество и являются инициаторами прогресса на селе [Звягинцев, Неуважаева 2015: 119]. По данным исследования, готовы мигрировать из села в город до 25 млн чел. при условии действенной аграрной политики и полного изменения условий жизни на селе. При этом исследователи феномена рурализации показывают, что при отсутствии модернизации аграрного производства и сохранении разницы между «городской» и «сельской» зарплатами реальное число мигрантов из города в село - менее 1 млн человек [Звягинцев, Неуважаева 2015: 128].

Причина, по которой городские переселенцы мало изучены, заключается в том, что они, по мнению социологов, «рассеяны по всей территории страны и проживают далеко не в каждом населенном пункте. В результате они почти не попадают в базы данных Росстата, RLMS и других масштабных исследований населения страны» [Звягинцев, Неуважаева 2015: 108].

Справедливость авторского вывода подтверждают более поздние статьи, которые появляются в периодической печати. Так в «Известиях» от 31 марта 2019 г. появилась статья М. Рубникович «Жизнь в деревне становится все более привлекательной», в которой собрана информация о переселенцах из города в село ${ }^{1}$. В основном это единичные случаи, но есть и более массовые. Предприниматель Алексей Конышев в 2012 г. подготовил проект «Поселок программистов» и разместил информацию в Интернете, чтобы узнать, найдутся ли желающие уехать из столицы в деревенскую тишину. На берегу Скоковского пруда в Кировской обл. он купил 17 га земли, подвел к ним электричество, воду, Интернет. В 2019 г. в поселке жили 9 семей. Предприниматель запустил летнюю школу по веб-разработке для старшеклассников и студентов. Это позволит зарабатывать, не покидая родной поселок ${ }^{2}$.

Таким образом, развитие города, появление новых динамических процессов требует изучения этих явлений. На этом пути могут помочь достижения чикагской социологической школы - их идеи и методы работы.

\section{Список литературы}

Вирт Л. 2016. Урбанизм как образ жжизни (пер. с англ.). М.: Strelka Press. 108 с. Звягинцев В.И., Неуважаева М.А. 2015. Переселенцы из города в сельскую местность: феномен «обратной миграции» в современной России. - Мир России. № 1. С. 101-135.

Зиммель Г. 2002. Большие города и духовная жизнь. - Логос. № 3-4. С. 23-34.

\footnotetext{
1 Рубникович М. 2019. Жизнь в деревне становится все более привлекательной. Доступ: https://iz.ru/859610/mariia-rubnikovich/pouekhavshie-molodye-rossiiane-pokidaiut-megapolisy (проверено 10.01.2021).

2 Там же.
} 
Ортега-и-Гассет Х. 1997. Восстание масс. - Избранные труды. М.: Весь Мир. $704 \mathrm{c}$.

Парк Р. 2006. Городское сообщество как пространственная конфигурация и моральный порядок. - Социологическое обозрение. Т. 5. № 1. С. 11-18.

Парк Р.Э. 2011. Город: предложения по исследованию человеческого поведения в городской среде. - Избранные очерки: сборник переводов. М.: Центр социал. научн.-информационных исследований. С. 19-56.

Савченко И.А. 2010. Лингвоидентичность и социокультурные условия развития этнообщностей. - Вестник Ленинградского государственного университета им. А.С. Пушкина. Т. 1. № 3. С. 281-297.

Савченко И.А. 2013. Средневековье постсовременности и глобальные трансформации. - Современные исследования социальных проблем: электронный научный журнал. № 5. Доступ: https://cyberleninka.ru/article/n/srednevekovie-postsovremennosti-i-globalnye-transformatsii/viewer (проверено 10.01.2021).

Шабаев Ю.П., Садохин А.П., Лабунова О.В., Сазонова Н.Н. 2018. Антропологическое понимание города и методология урбанистического изучения. - Мониторинг общественного мнения: Экономические и социальные перемены. № 3. С. 248-267.

Шпенглер О. 2009. Закат Европы. М.: Эксмо. 800 с.

DIMITRICHEVA Olga Ivanovna, Cand.Sci. (Philos.), Senior Researcher of the International Cross-Disciplinary Laboratory for Research Methods in Social Science, Associate Professor of the Chair of Philosophy, Sociology and Theory of Social Communication, Dobroljubov State Linguistics University of Nizhny Novgorod (31a Minina St, Nizhny Novgorod, Russia, 603950; Dimitr-olga@yandex.ru)

SAVCHENKO Irina Aleksandrovna, Dr.Sci. (Soc.), Head of the InternationalCross-Disciplinary Laboratory for Research Methods in Social Science, Professor of the Chair of Philosophy, Sociology and the Theory of Social Communication, Dobroljubov State Linguistics University of Nizhny Novgorod (31a Minina St, Nizhny Novgorod, Russia, 603950); Professor of the Chair of Philosophy, Nizhny Novgorod Academy of Ministry of Internal Affairs of Russian Federation (3 Ankudinovskoye Highway, Nizhny Novgorod, Russia, 603144; teosmaco@rambler.ru)

USTINKIN Sergey Vasilyevich, Dr.Sci. (Hist.), Professor; Director of the Volga Branch of the Federal Center of Theoretical and Applied Sociology, Russian Academy of Sciences (4 Holodny Lane, Nizhny Novgorod, Russia, 603000; sv.ustinkin@ gmail.com); Head of the International Cross-Disciplinary Laboratory for Studies of Global and Regional Sociopolitical Processes, Scientific Director of the Higher School of International Relations and World Politics, Dobroljubov State Linguistics University of Nizhny Novgorod (31a Minina St, Nizhny Novgorod, Russia, 603950; sv.ustinkin@gmail.com) PIKUNOV Oleg Igorevich, Master's Degree student of Dobroljubov State Linguistics University of Nizhny Novgorod (31a Minina St, Nizhny Novgorod, Russia, 603950; pikunovnglu@yandex.ru)

\section{RELEVANCE OF CHICAGO SCHOOL IDEAS IN THE FOCUS OF URBANIZATION AND RURALIZATION PROCESSES}

\footnotetext{
Abstract. The relevance of the ideas of the Chicago School of Sociology is explained by the fragmentation of comparative sociological studies of city and village and increases many times against the background of modern processes of urbanization and ruralization. The history of urban and rural sociology of city begins in the $19^{\text {th }}$ century, but today authoritative centers for the study of urban and rural communities, urban and rural cultures are not actively developing.

The authors show that modern parallel but multi-directional processes of urbanization and ruralization increase the relevance of the ideas of the Chicago School.
}

Keywords: urban and rural sociology, urban lifestyle, rural lifestyle, urban immigrants, hierarchy of values, ruralization, urbanization 